\title{
Lipaemia of the limbal vessels
}

\author{
A. J. BRON AND H. P. WILLIAMS \\ Department of Clinical Ophthalmology, Institute of Ophthalmology, University of London
}

A rise in the plasma triglycerides above a certain level imparts a milky opalescence to the plasma. This is termed lipaemia. Like other lipids the triglycerides are transported in the bloodstream within lipid-protein complexes, the plasma lipoproteins. Triglyceride of dietary origin is carried in the large lipoprotein particles called chylomicrons, while that synthesized within the body is carried in the pre-beta lipoprotein fraction of the plasma. An excess of either of these fractions is able to produce lipaemia (Rifkind, 1970).

Lactescence of the plasma in a specimen of withdrawn blood is sufficient to diagnose hypertriglyceridaemia and indicates the need for a full lipid analysis of the blood. However, hypertriglyceridaemia may also be diagnosed by clinical examination of the fundus oculi from the presence of lipaemia retinalis (Duke-Elder and Dobree, 1967). In this situation the retinal arteries and veins become indistinguishable, assume a milky, pinkish colour, and lose their light reflex. When the lipaemia is of severe degree the fundus colour may lighten also; this is due to lipaemia of the choroidal vessels. A sufficiently raised triglyceride blood level, whatever its cause, may produce lipaemia, which has thus been seen with primary hyperlipoproteinaemia of Types I, III, IV, and V (Fredrickson, Levy, and Lees, 1967), and in their secondary phenotypes (Vinger and Sachs, 1970). The observation of lipaemia retinalis may therefore be the first indication of a significant disorder of lipoprotein metabolism.

The present paper describes a new ocular sign of lipaemia observed in the vessels of the globe and limbus.

\section{Case history}

The patient was a 47-year-old white male weighing $73 \mathrm{~kg}$. who presented at Moorfields Eye Hospital with symptoms of blurred vision.

\section{Examination}

Each cornea exhibited a diffuse crystalline anterior stromal opacity and a dense broad arcus lipoides. A sister of the patient showed similar but less advanced corneal changes. A diagnosis of Schnyder's corneal dystrophy was made. Two other sisters had normal corneae, but all four siblings were found to have a systemic hyperlipoproteinaemia. The details of this unique association, in which there existed a disturbance of both plasma and corneal lipid, have been reported elsewhere (Bron, Williams, and Carruthers, I972; Garner and Tripathi, 1972).

The proband, who had a mixed Type III and Type V hyperlipoproteinaemia, was of particular interest in that his blood showed a gross elevation of plasma triglycerides (Table). 
Table Triglyceride before and after therapy

\begin{tabular}{lllll}
\hline Time of blood test & Normal & $\frac{\text { Before therapy }}{\text { fuly, 1970 }}$ & $\frac{\text { After therapy }}{\text { August, 1970 }}$ & $\frac{\text { Nov., 1970 }}{214}$ \\
\cline { 1 - 1 } & $\overline{106 \pm 58 \cdot 9}$ & $\frac{6,400}{5,240}$ & \\
\hline
\end{tabular}

The fasting triglyceride level was recorded as 6,400 and 5,240 mg. per cent. on separate occasions. The serum separated as a dense milky layer in withdrawn specimens of blood (Fig. I).

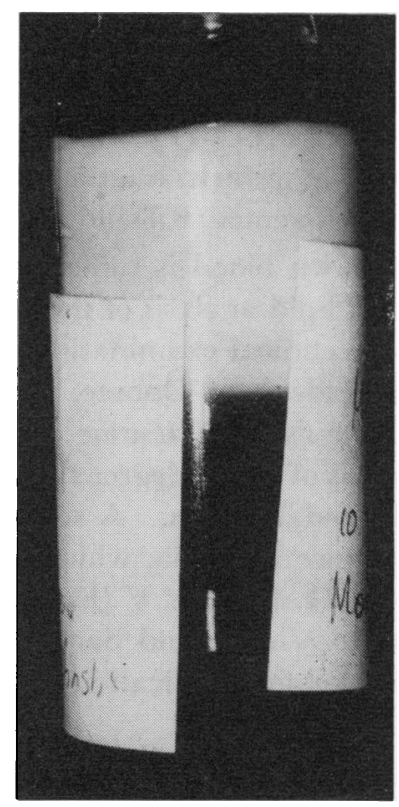

FIG. I Lipaemia of the serum in a specimen of clotted blood

The presence of the lipaemia in fasting blood suggested that lipaemia retinalis would be present, but the corneal opacities prevented examination of the fundi at that time.

\section{Treatment}

On May 7, I970, a left lamellar graft was performed. Although the graft remained clear, a persistent cloudiness of the bed of the graft remained and was regarded as an unual manifestation of Schnyder's dystrophy. A pinkish-orange discolouration of the retinal vessels was noted on fundus examination of the left eye and although the view was hazy because of the persistent cloudiness of the host stroma, a diagnosis of lipaemia retinalis was made.

\section{Further investigations}

For this reason attention was focused on the vessels of the globe itself in an attempt to demonstrate lipaemia at these more accessible sites. Biomicroscopic examination with the Zeiss slit lamp initially revealed no signs of lipaemia in the bulbar conjunctival vessels.

However, lipaemia of the limbal vessels was found at a number of sites where the limbal arcades passed into the lucid interval of the cornea between the margin of the posterior 
limbus and the outer edge of the arcus. These vessels formed a milk-white network against the dark background of the brown iris and their patency was demonstrated by observing the intermittent passage of red cells. At some sites flow was slow and an impression was gained of sludging of the red cell column. The red cells suspended in white plasma produced at times a distinct 'strawberries and cream' appearance. Fig. 2 shows the limbal vessels in the 5 o'clock meridian of the right eye at different points in time.

(a)

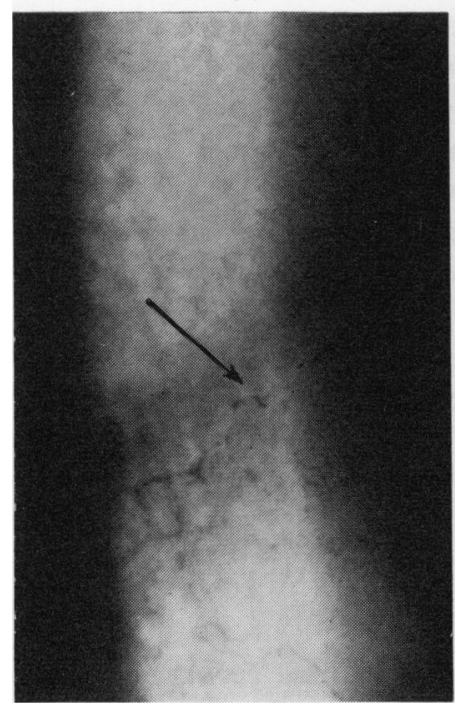

(b)

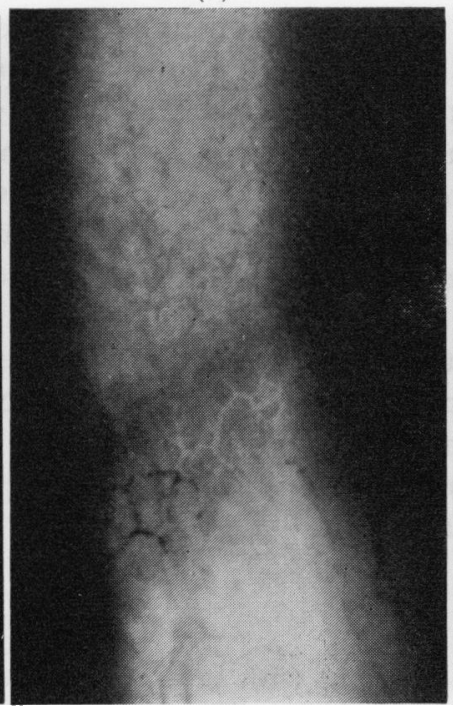

(c)

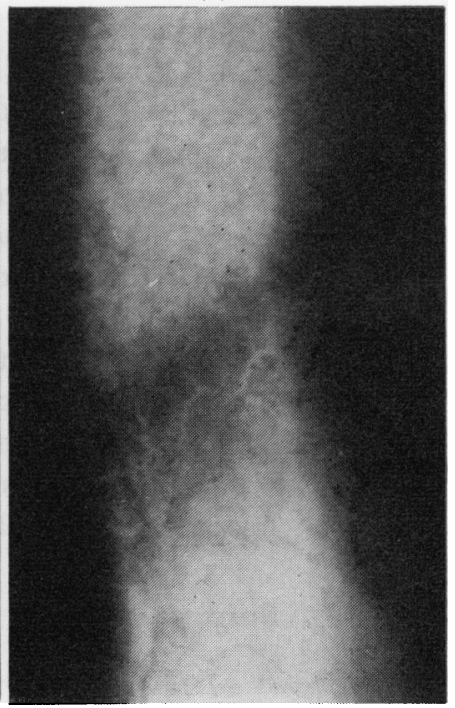

FIG. 2 Lipaemia of the limbal vessels. Right eye $(\mathrm{a}, \mathrm{b}, \mathrm{c})$ to demonstrate circulation of red cells through the lactescent limbal vessels. The arrow in $2 \mathrm{a}$ shows a red cell column which is absent in $\mathrm{b}$ and $\mathrm{c}$. Photographs taken consecutively within a few minutes, with a Brown macrocamera (Brown, 1970). $\quad \times 44$

It was found that lipaemia of the conjunctival vessels over the globe itself could be identified after the previous instillation of a vasoconstrictor such as cocaine or adrenaline. However, this lipaemia was seen with difficulty because of the lack of contrast between the white of the lipaemic vessels and the sclera itself.

The lipaemia noted in the limbal vessels was confirmed by a number of observers and was not noted to vary in degree at different times of the day. It was as marked in the fasting as in the non-fasting state. In normal subjects the rise in plasma chylomicrons which follows a meal is a transient phenomenon, owing to the action of lipases which hydrolyse the triglyceride fats and release the fatty acids. This lipase activity may be induced by the intravenous injection of heparin. A standard test to estimate the heparininduced lipoprotein lipase activity in this subject did not clear the limbal lipaemia. Although the lipase activity was within normal limits, plasma was not cleared by the dose of heparin given. In view of this, the persistence of the limbal lipaemia is not surprising.

Type III hyperlipoproteinaemia is associated with an increased incidence of peripheral vascular disease. For this reason the patient was treated by diet and daily Atromid-S and lost I I $\mathrm{kg}$. in weight in 6 weeks. 
Result

On slit-lamp examination at this time, the lipaemia of the limbal vessels had disappeared while the plasma triglycerides were estimated to be $2,300 \mu$ moles/litre (which is approximately equivalent to $214 \mathrm{mg}$. per cent. assuming the triglyceride to be triolein). Separated plasma, although still cloudy, was visibly less opaque to the naked eye than it had been before dieting.

\section{Discussion}

Lipaemia retinalis does not usually appear if the triglyceride level is below $2,500 \mathrm{mg}$ per cent. (Vinger and Sachs, I970). In the patient here described, lipaemia of the limbal vessels was present when the triglyceride levels were over 5,240 mg. per cent. and there was gross lipaemia of the blood, but the lipaemia of these vessels disappeared when the triglyceride level had fallen to $2 \mathrm{I} 4 \mathrm{mg}$. per cent. The exact triglyceride level at which the vessel lactescence was no longer visible is not known, but it may be stated that separated plasma still showed turbidity at a time when the limbal vessels were no longer lipaemic. To our knowledge lipaemia of the limbal vessels has not been described before. It is not mentioned, for instance, in a recent article dealing specifically with the ocular manifestations of hyperlipoproteinaemia (Vinger and Sachs, 1970). It seems likely that the sign is an indication simply of hypertriglyceridaemia without implication of a particular class of lipid disorder and that there is a threshold level of blood lipaemia at which the vessel lipaemia becomes apparent.

\section{Summary}

A 47-year-old male patient with Schnyder's central stromal corneal dystrophy exhibited an associated Type III hyperlipoproteinaemia. Hypertriglyceridaemia was responsible for a gross lipaemia of the blood. Lipaemia was apparent in the vessels of the limbal arcades and to a lesser extent in the vessels of the bulbar conjunctiva. This is thought to be a new clinical sign of lipaemia.

The authors wish to thank Mr. Derek Ainslie for permission to study the patient under his care and they also wish to express their thanks to Dr. J. Slack, of the MRG Clinical Genetics Unit of the Institute of Child Health, London, and to Dr. M. E. Carruthers, of the Department of Chemical Pathology, Institute of Ophthalmology, London, who performed the blood lipid analyses.

\section{References}

Bron, A. J., Williams, H. P., and Carruthers, M. E. (1972) Brit. F. Ophthal., 56, 383

BROWN, N. A. (I970) Ibid., 54, 697

DUKE-ELDER, S., and DOBREE, J. H. (1967) “System of Ophthalmology”, vol. Io, p. 452. Kimpton, London

FREDRICKSON, D. S., LEVY, R. I., and LEES, R. s. (1967) New Engl. F. Med., 276, 34, 94, I48, 2 I 5, and 273

GARNER, A., and TRIPATHI, R. c. (1972) Brit. F. Ophthal., 56, 400

RIFKIND, B. м. (1970) Brit. F. Hosp. Med., 4, 683

vinger, P. F., and SACHS, B. A. (1970) Amer. F. Ophthal., 70, 563 